\title{
Modelling cavitating flow around underwater missiles
}

\author{
Fabien Petitpas ${ }^{1}$, Richard Saurel ${ }^{1}$, Byoung-Kwon $\mathrm{Ahn}^{2}$ and Sungho $\mathrm{Ko}^{2}$ \\ ${ }^{1}$ Aix-Marseille University, Marseille, France \\ ${ }^{2}$ Chungnam National University, Daejeon, Korea
}

\begin{abstract}
The diffuse interface model of Saurel et al. (2008) is used for the computation of compressible cavitating flows around underwater missiles. Such systems use gas injection and natural cavitation to reduce drag effects. Consequently material interfaces appear separating liquid and gas. These interfaces may have a really complex dynamics such that only a few formulations are able to predict their evolution. Contrarily to front tracking or interface reconstruction method the interfaces are computed as diffused numerical zones, that are captured in a routinely manner, as is done usually with gas dynamics solvers for shocks and contact discontinuity. With the present approach, a single set of partial differential equations is solved everywhere, with a single numerical scheme. This leads to very efficient solvers.

The algorithm derived in Saurel et al. (2009) is used to compute cavitation pockets around solid bodies. It is first validated against experiments done in cavitation tunnel at CNU. Then it is used to compute flows around high speed underwater systems (Shkval-like missile). Performance data are then computed showing method ability to predict forces acting on the system.
\end{abstract}

KEY WORDS: Diffuse interface model; Cavitation pockets prediction; Shkval torpedo.

\section{INTRODUCTION}

Underwater vehicles with high velocity capabilities have been built in Russia, Ukraine, USA, Germany and others. These systems use gas devices in order to reduce drag effects and reach velocities of the order of $500 \mathrm{~km} / \mathrm{h}$. In these systems, gas is injected through orifices at the nose as well as through a rocket nozzle. The gas injected at nose is used to reduce drag, while those injected through the nozzle is used to achieve system's propulsion. Natural cavitation can also be used to reduce drag. A schematic representation of a possible system is shown hereafter:

In any case, interfaces separating fluids appear during underwater high speed motion. These interfaces may be a consequence of injected gas or gas bubbles and pocket growth due to liquid expansion at geometrical singularities.

The numerical simulation of flows around hypervelocity underwater projectiles, in the presence of compressible effects and cavitation, has been addressed in a pioneer work by Saurel et al. (1999). The flow model used was considering liquid and vapour at thermodynamic equilibrium. The presence of non-condensable gases, such as propulsion gases or air, separated from the liquid by an interface was an issue. Indeed, the mixture equation of state was a consequence of the liquid-vapour phase diagram and the presence of a non-

Corresponding author: Fabien Petitpas

e-mail:fabien.petitpas@polytech.univ-mrs.fr condensable phase was a difficult extension in this frame.

Later, Saurel and Le Metayer (2001) proposed a multiphase flow model able to deal with dynamic interface creation in cavitating systems, as well as interfaces separating non-condensable gases and liquids. However, mass transfer modelling was difficult, as the flow model was involving at least two velocities. Thermodynamically consistent models of mass transfer when both phases are compressible were not mature at that time.

Le Metayer et al. (2005) proposed a method able to solve evaporation fronts dynamics in metastable liquid in multidimensions. This method was efficient but difficult to implement and inappropriate for possible condensation effects.

On the basis of the Kapila et al. (2001) multi-temperature multi-phase flow model, Saurel et al. (2008) developed another method to deal with phase transition and cavitation fronts. This model was able to deal with both condensable and non-condensable fluids. Thanks to the algorithm developed in Saurel et al. (2009) efficient resolution of this flow model was possible. Petitpas et al. (2009a) generalized the flow model to an arbitrary number of fluids and shown that efficient computations of flows around hypervelocity underwater vehicles was possible.

In the present work we consider the approaches described in these last references. Indeed, among the various methods able to deal with interface problems, the present one has some advantages. 


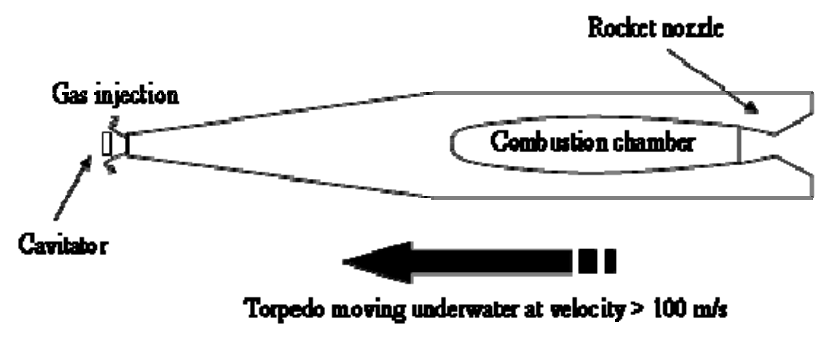

Fig. 1 Schematic representation of a possible underwater missile.

\section{Review of existing models and method}

The most natural way to deal with material interfaces is to consider a Lagrangian description. Such approach is efficient in solid mechanics as deformations are limited. In fluid mechanics, deformations are unbounded and mesh distortions become so large that computational failure occurs rapidly. Arbitrary Lagrangian Eulerian methods (ALE) improve their capabilities, but remain inappropriate for many applications.

The topic of interfaces computation with compressible materials has been (and is still) very important in many defense applications. In the US, interface reconstruction methods have been widely used (Noh, 1976, Hirt and Nichols, 1981). However, the computation of thermodynamic variables in mixture cells was published only long time after (Miller and Puckett, 1996). It is however clear that momentum and energy are not strictly conserved. It is also quite obvious that these methods are unable to deal with mass transfer at interfaces.

Another class of methods deals with interfaces tracking (Glimm et al., 1998). These methods are difficult to code, as each flow topology has to be accounted for. Moreover, permeable interfaces with compressible effects are still an issue with these methods.

More recently, level set methods became popular, in particular with the Ghost Fluid method of Fedkiw et al. (1999). These methods are attractive as the interface remain sharp but have difficulties with large density ratios, conservation respect and again with mass transfer at interfaces.

All preceding approaches try to maintain the interfaces as sharp as possible. Oppositely, models and methods have been promoted since Saurel and Abgrall (1999) to consider these interfaces as diffuse zones. Conventional methods used in compressible flow dynamics consider shocks and contact discontinuities as diffused zones. The reason is that it is much more efficient to capture them rather than to track or fit them. This 'capturing' philosophy was promoted a long time ago, first by Von Neumann and Richtmyer (1950) with the artificial viscosity method and then by Godunov (1959) with the help of Riemann solvers.

In our approach we follow the approach initiated by Godunov (both at the modeling and numerical levels) and extend it to hyperbolic systems with stiff relaxation effects. It consists in:
- The building of hyperbolic systems thermodynamically compatible, in particular regarding the entropy inequality.

- The building of numerical schemes valid at each point: shocks, expansions, contact discontinuities. In this aim, the equations have to be as far as possible under conservative form. In the present context, the equations must also be valid at interfaces and particularly preserve interface conditions. These conditions, when mass transfer is absent correspond to equal normal velocities and equal pressures.

In the present study the following ingredients are used:

- The flow model for diffuse interfaces presented in Kapila et al. (2001) and Saurel et al. (2008).

- The Stiffened Gas equations of state presented in Le Métayer et al. (2004).

- The numerical scheme of Saurel et al. (2009).

The main advantages with this approach are:

- Simplicity. The same equations are solved everywhere with a unique numerical scheme.

- Extension to extra physics is possible: capillary effects (Perigaud and Saurel, 2005), mass transfer (Saurel et al., 2008), combustion and detonations (Petitpas et al., 2009b), elastic solid - fluid interfaces (Favrie et al., 2009), granular materials (Saurel et al., 2010).

- Dynamic interface creation. This is the only method able to deal with the dynamic appearance of interfaces (not present initially). This is of paramount importance in the present application, where a flow with pure liquid is present initially.

Last, as the gas dynamics Euler equations correspond to the single phase limit of these equations, single phase compressible flows of gases and liquids are accurately predicted. This is important for example for nozzle flow computations.

The first part of this paper recalls the flow model. The numerical method is presented in the second part. Then, the third part is focused on validations against experiments in water tunnels done at $\mathrm{CNU}$ on various body shapes. Numerical simulations predict gas pocket sizes in agreement with experimental observations. The fourth and last part deals with more realistic torpedo geometries. Torpedo inclination effects are investigated. In each case, pressure drag and lift are computed.

\section{DIFFUSE INTERFACE MODEL AND PROPERTIES}

The flow model used in the computations is presented here in the context of an arbitrary number of fluids. This model is fully derived in Kapila et al. (2001) in the case of two phase flows. In the present application, three phases at least are necessary due to propulsion gases injected through the nozzle and those injected through the torpedo nose. 
The model is able to compute interfaces and fluid mixtures evolving under a unique pressure and unique velocity. It is thus particularly well adapted to cavitation studies with dynamic appearances of gas pockets:

$$
\begin{aligned}
& \frac{\partial \alpha_{\mathrm{k}}}{\partial \mathrm{t}}+\overrightarrow{\mathrm{u}} \cdot \operatorname{grad}\left(\alpha_{\mathrm{k}}\right)=\alpha_{\mathrm{k}}\left(\frac{\rho \mathrm{c}^{2}}{\rho_{\mathrm{k}} \mathrm{c}_{\mathrm{k}}{ }^{2}}-1\right) \operatorname{div}(\overrightarrow{\mathrm{u}}) \\
& \frac{\partial \alpha_{\mathrm{k}} \rho_{\mathrm{k}}}{\partial \mathrm{t}}+\operatorname{div}\left(\alpha_{\mathrm{k}} \rho_{\mathrm{k}} \overrightarrow{\mathrm{u}}\right)=0 \\
& \frac{\partial \rho \overrightarrow{\mathrm{u}}}{\partial \mathrm{t}}+\operatorname{div}(\rho \overrightarrow{\mathrm{u}} \otimes \overrightarrow{\mathrm{u}}+\mathrm{p} \overline{\mathrm{I}})=\overrightarrow{0} \\
& \frac{\partial \rho \mathrm{E}}{\partial \mathrm{t}}+\operatorname{div}((\rho \mathrm{E}+\mathrm{p}) \overrightarrow{\mathrm{u}})=0
\end{aligned}
$$

where $\alpha, \rho, \overrightarrow{\mathrm{u}}=(\mathrm{u}, \mathrm{v}, \mathrm{w}), \mathrm{p}, \mathrm{E} \quad\left(\mathrm{E}=\mathrm{e}+\frac{\|\overrightarrow{\mathrm{u}}\|^{2}}{2}\right)$, and $\mathrm{e}$ represent respectively the volume fraction, the density, the velocity vector, the pressure, the mixture total energy and the mixture internal energy.

The mixture internal energy is defined as,

$$
\mathrm{e}=\sum_{\mathrm{k}} \mathrm{Y}_{\mathrm{k}} \mathrm{e}_{\mathrm{k}}\left(\rho_{\mathrm{k}}, \mathrm{p}\right)
$$

and the mass fractions are given by: $Y_{k}=\frac{(\alpha \rho)_{k}}{\rho}$.

The mixture density is defined by $\rho=\sum_{\mathrm{k}} \alpha_{\mathrm{k}} \rho_{\mathrm{k}}$.

Each fluid is governed by its own convex equation of state (EOS),

$\mathrm{e}_{\mathrm{k}}=\mathrm{e}_{\mathrm{k}}\left(\rho_{\mathrm{k}}, \mathrm{p}\right)$,

that allows the determination of the phases' sound speed,

$\mathrm{c}_{\mathrm{k}}=\mathrm{c}_{\mathrm{k}}\left(\rho_{\mathrm{k}}, \mathrm{p}\right)$.

In the particular case of fluids governed by the stiffened gas EOS,

$p_{k}=\left(\gamma_{k}-1\right) \rho_{k}\left(e_{k}-q_{k}\right)-\gamma_{k} p_{\infty \mathrm{k}}$,

the resulting mixture EOS reads,

$$
p\left(\alpha_{k}, \rho_{k}, e\right)=\frac{\rho e-\sum_{k}\left(\frac{\alpha_{k} \gamma_{k} p_{\infty o k}}{\gamma_{k}-1}+\alpha_{k} \rho_{k} q_{k}\right)}{\sum_{k}\left(\frac{\alpha_{k}}{\gamma_{k}-1}\right)}
$$

System (1) is hyperbolic with the three wave's speeds $\mathrm{u}, \mathrm{u}+\mathrm{c}_{\mathrm{w}}$ and $\mathrm{u}-\mathrm{c}_{\mathrm{w}}$.

where $c_{w}$ is the multiphase extension of the non-monotonic Wood (1930) sound speed: $\frac{1}{\rho c_{\mathrm{w}}^{2}}=\sum_{\mathrm{k}} \frac{\alpha_{\mathrm{k}}}{\rho_{\mathrm{k}} \mathrm{c}_{\mathrm{k}}^{2}}$.

System (1) is also thermodynamically consistent as it agrees with the second law of thermodynamics.

\section{NUMERICAL METHOD}

It has been shown in Saurel et al. (2009) that System (1) presents inherent difficulties for its numerical resolution. To solve efficiently this system, another extended system is considered, apparently more complex. However, with the extended model, there is no difficulty to preserve volume fraction positivity. Also, the sound speed with the new model is monotonic with respect to volume fractions. These features facilitate numerical resolution.

Nevertheless, to recover solutions of the mechanical equilibrium model (1), stiff pressure relaxation is used, preserving also volume fraction positivity.

Therefore, the model is solved in a sequence of three steps:

- Solve a pressure non-equilibrium flow model with appropriate hyperbolic solver.

- Relax the pressure toward mechanical equilibrium.

- Reset the internal energies.

Each step is presented hereafter.

The pressure non-equilibrium model reads:

$$
\begin{aligned}
& \frac{\partial \alpha_{\mathrm{k}}}{\partial \mathrm{t}}+\overrightarrow{\mathrm{u}} \cdot \operatorname{grad}\left(\alpha_{\mathrm{k}}\right)=\alpha_{\mathrm{k}} \mu\left(\mathrm{p}_{\mathrm{k}}-\mathrm{p}_{*}\right) \\
& \frac{\partial \alpha_{\mathrm{k}} \rho_{\mathrm{k}}}{\partial \mathrm{t}}+\operatorname{div}\left(\alpha_{\mathrm{k}} \rho_{\mathrm{k}} \overrightarrow{\mathrm{u}}\right)=0 \\
& \frac{\partial \rho \overrightarrow{\mathrm{u}}}{\partial \mathrm{t}}+\operatorname{div}\left(\rho \overrightarrow{\mathrm{u}} \otimes \overrightarrow{\mathrm{u}}+\left(\sum_{\mathrm{k}} \alpha_{\mathrm{k}} \mathrm{p}_{\mathrm{k}}\right)=\overrightarrow{\mathrm{I}}\right)=\overrightarrow{0} \\
& \frac{\partial \alpha_{\mathrm{k}} \rho_{\mathrm{k}} \mathrm{e}_{\mathrm{k}}}{\partial \mathrm{t}}+\operatorname{div}\left(\alpha_{1} \rho_{1} \mathrm{e}_{1} \overrightarrow{\mathrm{u}}\right)+\alpha_{1} \mathrm{p}_{1} \operatorname{div}(\overrightarrow{\mathrm{u}})=-\alpha_{\mathrm{k}} \mathrm{p}_{\mathrm{I}} \mu\left(\mathrm{p}_{\mathrm{k}}-\mathrm{p}_{*}\right)
\end{aligned}
$$

Combination of the internal energy equations with mass and momentum equations results in the additional mixture energy equation:

$$
\begin{aligned}
& \frac{\partial \rho\left(\sum_{\mathrm{k}} \mathrm{Y}_{\mathrm{k}} \mathrm{e}_{\mathrm{k}}+\frac{1}{2}\|\overrightarrow{\mathrm{u}}\|^{2}\right)}{\partial \mathrm{t}} \\
& +\operatorname{div}\left\{\left(\rho\left(\sum_{\mathrm{k}} \mathrm{Y}_{\mathrm{k}} \mathrm{e}_{\mathrm{k}}+\frac{1}{2}\|\overrightarrow{\mathrm{u}}\|^{2}\right)+\sum_{\mathrm{k}} \alpha_{\mathrm{k}} \mathrm{p}_{\mathrm{k}}\right) \overrightarrow{\mathrm{u}}\right\}=0
\end{aligned}
$$


This extra equation will be important during numerical resolution, in order to correct inaccuracies due to the numerical approximation of the non-conservative internal energy equations in the presence of shocks.

This model exhibits a nice feature with respect to the mixture sound speed. Indeed the mixture sound speed,

$$
\mathrm{c}_{\mathrm{f}}^{2}=\sum_{\mathrm{k}} \mathrm{Y}_{\mathrm{k}} \mathrm{c}_{\mathrm{k}}^{2}
$$

has a monotonic behavior versus volume and mass fractions and represents the frozen mixture speed of sound. The model is thus hyperbolic with waves speeds: $u-c_{f}, u, u+c_{f}$.

System (3) is aimed to replace resolution of System (1) by the three steps method, mentioned previously. During the first step, System (3) is solved in absence of relaxation terms $(\mu=0)$. Then relaxation terms are considered and are assumed stiff. In other word, the mechanical equilibrium solution is obtained at the end of the second step. It can be proved by asymptotic analysis that such strategy yields precisely to solutions of System (1).

Numerical resolution of the pressure non-equilibrium model in the limit of stiff pressure relaxation is then addressed. In regular zones, this model is self consistent. But in the presence of shocks the internal energy equations are inappropriate. To correct the thermodynamic state predicted by these equations in the presence of shocks, the total mixture energy equation is used. This correction is valid on both sides of an interface, when the flow tends to the single phase limits. The details of this correction will be examined further. For now, the pressure non-equilibrium system is augmented by a redundant equation regarding the total mixture energy. The system to consider during numerical resolution thus involves $3 \mathrm{~N}+2$ equations ( $\mathrm{N}$ being the number of fluids):

$$
\begin{aligned}
& \frac{\partial \alpha_{\mathrm{k}}}{\partial \mathrm{t}}+\overrightarrow{\mathrm{u}} \cdot \operatorname{grad}\left(\alpha_{\mathrm{k}}\right)=\alpha_{\mathrm{k}} \mu\left(\mathrm{p}_{\mathrm{k}}-\mathrm{p}_{*}\right) \\
& \frac{\partial \alpha_{\mathrm{k}} \rho_{\mathrm{k}}}{\partial \mathrm{t}}+\operatorname{div}\left(\alpha_{\mathrm{k}} \rho_{\mathrm{k}} \overrightarrow{\mathrm{u}}\right)=0 \\
& \frac{\partial \alpha_{\mathrm{k}} \rho_{\mathrm{k}} \mathrm{e}_{\mathrm{k}}}{\partial \mathrm{t}}+\operatorname{div}\left(\alpha_{1} \rho_{1} \mathrm{e}_{1} \overrightarrow{\mathrm{u}}\right)+\alpha_{1} \mathrm{p}_{1} \operatorname{div}(\overrightarrow{\mathrm{u}})=-\alpha_{\mathrm{k}} \mathrm{p}_{\mathrm{I}} \mu\left(\mathrm{p}_{\mathrm{k}}-\mathrm{p}_{*}\right) \\
& \frac{\partial \rho \overrightarrow{\mathrm{u}}}{\partial \mathrm{t}}+\operatorname{div}\left(\rho \overrightarrow{\mathrm{u}} \otimes \overrightarrow{\mathrm{u}}+\left(\sum_{\mathrm{k}} \alpha_{\mathrm{k}} \mathrm{p}_{\mathrm{k}}\right)=\overrightarrow{\mathrm{I}}\right)=\overrightarrow{0}
\end{aligned}
$$$$
\partial \rho\left(\sum_{\mathrm{k}} \mathrm{Y}_{\mathrm{k}} \mathrm{e}_{\mathrm{k}}+\frac{1}{2}\|\overrightarrow{\mathrm{u}}\|^{2}\right)
$$$$
\partial \mathrm{t}
$$$$
+\operatorname{div}\left\{\left(\rho\left(\sum_{\mathrm{k}} \mathrm{Y}_{\mathrm{k}} \mathrm{e}_{\mathrm{k}}+\frac{1}{2}\|\overrightarrow{\mathrm{u}}\|^{2}\right)+\sum_{\mathrm{k}} \alpha_{\mathrm{k}} \mathrm{p}_{\mathrm{k}}\right) \overrightarrow{\mathrm{u}}\right\}=0
$$

We are now going to present the three steps of the numerical method in the context of $3 \mathrm{D}$ flows with an arbitrary number of phases.

\section{Hyperbolic solver}

The hyperbolic solver is used to solve system (4) in the absence of relaxation terms $(\mu=0)$. At each cell boundary, the flow is assumed locally one-dimensional. The first ingredient corresponds to the Riemann solver used to compute the fluxes that cross each cell boundary. Then the variables are updated with a Godunov type method.

\section{HLLC type Riemann Solver (Toro et al., 1994)}

Consider a cell boundary separating a left state (L) and a right state $(\mathrm{R})$. The left- and right-facing wave's speeds are readily obtained, following Davis (1988) estimates:

$\mathrm{S}_{\mathrm{R}}=\max \left(\mathrm{u}_{\mathrm{L}}+\mathrm{c}_{\mathrm{L}}, \mathrm{u}_{\mathrm{R}}+\mathrm{c}_{\mathrm{R}}\right)$
$\mathrm{S}_{\mathrm{L}}=\min \left(\mathrm{u}_{\mathrm{L}}-\mathrm{c}_{\mathrm{L}}, \mathrm{u}_{\mathrm{R}}-\mathrm{c}_{\mathrm{R}}\right)$,

where the frozen sound speed still obeys to the relation:

$\mathrm{c}^{2}=\sum_{\mathrm{k}} \mathrm{Y}_{\mathrm{k}} \mathrm{c}_{\mathrm{k}}^{2}$

The intermediate wave speed (or contact discontinuity speed) is estimated under HLL approximation,

$\mathrm{S}_{\mathrm{M}}=\frac{\left(\rho \mathrm{u}^{2}+\mathrm{p}\right)_{\mathrm{L}}-\left(\rho \mathrm{u}^{2}+\mathrm{p}\right)_{\mathrm{R}}-\mathrm{S}_{\mathrm{L}}(\rho \mathrm{u})_{\mathrm{L}}+\mathrm{S}_{\mathrm{R}}(\rho \mathrm{u})_{\mathrm{R}}}{(\rho \mathrm{u})_{\mathrm{L}}-(\rho \mathrm{u})_{\mathrm{R}}-\mathrm{S}_{\mathrm{L}} \rho_{\mathrm{L}}+\mathrm{S}_{\mathrm{R}} \rho_{\mathrm{R}}}$,

with the mixture density and mixture pressure defined previously.

From these wave speeds, the following variable states are determined:

$$
\begin{aligned}
& \left(\alpha_{\mathrm{k}} \rho_{\mathrm{k}}\right)_{\mathrm{R}}^{*}=\left(\alpha_{\mathrm{k}} \rho_{\mathrm{k}}\right)_{\mathrm{R}} \frac{\mathrm{S}_{\mathrm{R}}-\mathrm{u}_{\mathrm{R}}}{\mathrm{S}_{\mathrm{R}}-\mathrm{S}_{\mathrm{M}}}, \\
& \left(\alpha_{\mathrm{k}} \rho_{\mathrm{k}}\right)_{\mathrm{L}}^{*}=\left(\alpha_{\mathrm{k}} \rho_{\mathrm{k}}\right)_{\mathrm{L}} \frac{\mathrm{S}_{\mathrm{L}}-\mathrm{u}_{\mathrm{L}}}{\mathrm{S}_{\mathrm{L}}-\mathrm{S}_{\mathrm{M}}} \\
& \mathrm{p}^{*}=\mathrm{p}_{\mathrm{R}}+\rho_{\mathrm{R}} \mathrm{u}_{\mathrm{R}}\left(\mathrm{u}_{\mathrm{R}}-\mathrm{S}_{\mathrm{R}}\right)-\rho_{\mathrm{R}}^{*} \mathrm{~S}_{\mathrm{M}}\left(\mathrm{S}_{\mathrm{M}}-\mathrm{S}_{\mathrm{R}}\right),
\end{aligned}
$$$$
\text { with } \rho_{\mathrm{R}}^{*}=\sum_{\mathrm{k}}\left(\alpha_{\mathrm{k}} \rho_{\mathrm{k}}\right)_{\mathrm{R}}^{*}
$$$$
\mathrm{E}_{\mathrm{R}}^{*}=\frac{\rho_{\mathrm{R}} \mathrm{E}_{\mathrm{R}}\left(\mathrm{u}_{\mathrm{R}}-\mathrm{S}_{\mathrm{R}}\right)+\mathrm{p}_{\mathrm{R}} \mathrm{u}_{\mathrm{R}}-\mathrm{p}^{*} \mathrm{~S}_{\mathrm{M}}}{\rho_{\mathrm{R}}^{*}\left(\mathrm{~S}_{\mathrm{M}}-\mathrm{S}_{\mathrm{R}}\right)},
$$$$
\mathrm{E}_{\mathrm{L}}^{*}=\frac{\rho_{\mathrm{L}} \mathrm{E}_{\mathrm{L}}\left(\mathrm{u}_{\mathrm{L}}-\mathrm{S}_{\mathrm{L}}\right)+\mathrm{p}_{\mathrm{L}} \mathrm{u}_{\mathrm{L}}-\mathrm{p}^{*} \mathrm{~S}_{\mathrm{M}}}{\rho_{\mathrm{L}}^{*}\left(\mathrm{~S}_{\mathrm{M}}-\mathrm{S}_{\mathrm{L}}\right)}
$$

with $\mathrm{E}=\sum_{\mathrm{k}} \mathrm{Y}_{\mathrm{k}} \mathrm{e}_{\mathrm{k}}+\frac{1}{2}\|\overrightarrow{\mathrm{u}}\|^{2}$. 
The volume fraction jump is readily obtained, as in the absence of relaxation effects the volume fraction is constant along fluid trajectories,

$$
\alpha_{\mathrm{kR}}^{*}=\alpha_{\mathrm{kR}}, \alpha_{\mathrm{kL}}^{*}=\alpha_{\mathrm{kL}}
$$

As the volume fraction is constant across left- and rightfacing waves, the fluid density is determined from the preceding relations:

$$
\rho_{\mathrm{kR}, \mathrm{L}}^{*}=\rho_{\mathrm{kR}, \mathrm{L}} \frac{\mathrm{u}_{\mathrm{R}, \mathrm{L}}-\mathrm{S}_{\mathrm{R}, \mathrm{L}}}{\mathrm{S}_{\mathrm{M}}-\mathrm{S}_{\mathrm{R}, \mathrm{L}}} .
$$

The transverse velocities jumps are also readily obtained,

$$
\mathrm{v}_{\mathrm{R}}^{*}=\mathrm{v}_{\mathrm{R}}, \mathrm{v}_{\mathrm{L}}^{*}=\mathrm{v}_{\mathrm{L}}, \mathrm{w}_{\mathrm{R}}^{*}=\mathrm{w}_{\mathrm{R}}, \mathrm{w}_{\mathrm{L}}^{*}=\mathrm{w}_{\mathrm{L}}
$$

Internal energy jumps are determined with the help of the Hugoniot relation (Saurel et al., 2007). Let us consider the example of fluids governed by the stiffened gas EOS. With the help of the EOS, the phasic pressures are constrained along their Hugoniot curves as functions only of the corresponding phase density:

$$
\mathrm{p}_{\mathrm{k}}^{*}\left(\rho_{\mathrm{k}}^{*}\right)=\left(\mathrm{p}_{\mathrm{k}}+\mathrm{p}_{\infty \mathrm{k}}\right) \frac{\left(\gamma_{\mathrm{k}}-1\right) \rho_{\mathrm{k}}-\left(\gamma_{\mathrm{k}}+1\right) \rho_{\mathrm{k}}^{*}}{\left(\gamma_{\mathrm{k}}-1\right) \rho_{\mathrm{k}}^{*}-\left(\gamma_{\mathrm{k}}+1\right) \rho_{\mathrm{k}}}-\mathrm{p}_{\infty \mathrm{k}}
$$

The phase's internal energies are then determined from the EOS: $\mathrm{e}_{\mathrm{kR}}^{*}=\mathrm{e}_{\mathrm{kR}}^{*}\left(\mathrm{p}_{\mathrm{k}}^{*}, \rho_{\mathrm{k}}^{*}\right)$.

Equipped with this HLLC type approximate Riemann solver, the next step is to develop a Godunov type scheme.

\section{Godunov type method}

In the absence of relaxation terms, the conservative part of System (4) is updated with the conventional Godunov scheme on 3D Cartesian grids:

$$
\begin{aligned}
\mathrm{U}_{\mathrm{i}, \mathrm{j}, 1}^{\mathrm{n}+1}=\mathrm{U}_{\mathrm{i}, \mathrm{j}, 1}^{\mathrm{n}} & -\frac{\Delta \mathrm{t}}{\Delta \mathrm{x}}\left(\mathrm{F}^{*}\left(\mathrm{U}_{\mathrm{i}, \mathrm{j}, 1}^{\mathrm{n}}, \mathrm{U}_{\mathrm{i}+\mathrm{j}, \mathrm{j}, 1}^{\mathrm{n}}\right)-\mathrm{F}^{*}\left(\mathrm{U}_{\mathrm{i}-1, \mathrm{j}, 1,1}^{\mathrm{n}} \mathrm{U}_{\mathrm{i}, \mathrm{j}, 1}^{\mathrm{n}}\right)\right) \\
& -\frac{\Delta \mathrm{t}}{\Delta \mathrm{y}}\left(\mathrm{G}^{*}\left(\mathrm{U}_{\mathrm{i}, \mathrm{j}, 1}^{\mathrm{n}}, \mathrm{U}_{\mathrm{i}, \mathrm{j}+1,1}^{\mathrm{n}}\right)-\mathrm{G}^{*}\left(\mathrm{U}_{\mathrm{i}, \mathrm{j}-1,1}^{\mathrm{n}}, \mathrm{U}_{\mathrm{i}, \mathrm{j}, 1}^{\mathrm{n}}\right)\right) \\
& -\frac{\Delta \mathrm{t}}{\Delta \mathrm{z}}\left(\mathrm{H}^{*}\left(\mathrm{U}_{\mathrm{i}, \mathrm{j}, 1}^{\mathrm{n}}, \mathrm{U}_{\mathrm{i}, \mathrm{j}, 1+1}^{\mathrm{n}}\right)-\mathrm{H}^{*}\left(\mathrm{U}_{\mathrm{i}, \mathrm{j}, 1-1}^{\mathrm{n}}, \mathrm{U}_{\mathrm{i}, \mathrm{j}, 1}^{\mathrm{n}}\right)\right)
\end{aligned}
$$

where $\mathrm{U}=\left((\alpha \rho)_{\mathrm{k}}, \rho \mathrm{u}, \rho \mathrm{v}, \rho \mathrm{w}, \rho \mathrm{E}\right)^{\mathrm{T}}$ and flux vectors:

$$
\begin{aligned}
& \mathrm{F}=\left((\alpha \rho)_{\mathrm{k}} \mathrm{u}, \rho \mathrm{u}^{2}+\mathrm{p}, \rho \mathrm{uv}, \rho \mathrm{uw},(\rho \mathrm{E}+\mathrm{p}) \mathrm{u}\right)^{\mathrm{T}}, \\
& \mathrm{G}=\left((\alpha \rho)_{\mathrm{k}} \mathrm{v}, \rho \mathrm{uv}, \rho \mathrm{v}^{2}+\mathrm{p}, \rho \mathrm{vw},(\rho \mathrm{E}+\mathrm{p}) \mathrm{v}\right)^{\mathrm{T}}, \\
& \mathrm{H}=\left((\alpha \rho)_{\mathrm{k}} \mathrm{w}, \rho \mathrm{uw}, \rho \mathrm{vw}, \rho \mathrm{w}^{2}+\mathrm{p},(\rho \mathrm{E}+\mathrm{p}) \mathrm{w}\right)^{\mathrm{T}}, \\
& \text { and } \mathrm{E}=\sum_{\mathrm{k}} \mathrm{Y}_{\mathrm{k}} \mathrm{e}_{\mathrm{k}}+\frac{1}{2} \mathrm{u}^{2}+\frac{1}{2} \mathrm{v}^{2}+\frac{1}{2} \mathrm{w}^{2}
\end{aligned}
$$

and $\mathrm{p}=\sum_{\mathrm{k}} \alpha_{\mathrm{k}} \mathrm{p}_{\mathrm{k}}$

The volume fraction equation is also updated using the Godunov method for advection equations:

$$
\begin{aligned}
\alpha_{\mathrm{ki}, \mathrm{j}, \mathrm{l}}^{\mathrm{n}+1} & =\alpha_{\mathrm{ki}, \mathrm{j}, \mathrm{l}}^{\mathrm{n}} \\
& -\frac{\Delta \mathrm{t}}{\Delta \mathrm{x}}\left(\left(\mathrm{u} \alpha_{\mathrm{k}}\right)_{\mathrm{i}+1 / 2, \mathrm{j}, 1}^{*}-\left(\mathrm{u} \alpha_{\mathrm{k}}\right)_{\mathrm{i}-1 / 2, \mathrm{j}, 1}^{*}-\alpha_{\mathrm{ki}, \mathrm{j}, 1}^{\mathrm{n}}\left(\mathrm{u}_{\mathrm{i}+1 / 2, \mathrm{j}, 1}^{*}-\mathrm{u}_{\mathrm{i}-1 / 2, \mathrm{j}, 1}^{*}\right)\right) \\
& -\frac{\Delta \mathrm{t}}{\Delta \mathrm{y}}\left(\left(\mathrm{v} \alpha_{\mathrm{k}}\right)_{\mathrm{i}, \mathrm{j}+1 / 2,1}^{*}-\left(\mathrm{v} \alpha_{\mathrm{k}}\right)_{\mathrm{i}, \mathrm{j}-1 / 2,1}^{*}-\alpha_{\mathrm{ki}, \mathrm{j}, 1}^{\mathrm{n}}\left(\mathrm{v}_{\mathrm{i}, j+1 / 2,1}^{*}-\mathrm{v}_{\mathrm{i}, \mathrm{j}-1 / 2,1}^{*}\right)\right) \\
& -\frac{\Delta \mathrm{t}}{\Delta \mathrm{z}}\left(\left(\mathrm{w} \alpha_{\mathrm{k}}\right)_{\mathrm{i}, \mathrm{j}, 1+1 / 2}^{*}-\left(\mathrm{v} \alpha_{\mathrm{k}}\right)_{\mathrm{i}, \mathrm{j}, 1-1 / 2}^{*}-\alpha_{\mathrm{ki}, \mathrm{j}, 1}^{\mathrm{n}}\left(\mathrm{w}_{\mathrm{i}, \mathrm{j}, 1+1 / 2}^{*}-\mathrm{w}_{\mathrm{i}, \mathrm{j}, 1-1 / 2}^{*}\right)\right)
\end{aligned}
$$

This scheme guarantees volume fraction positivity during the hyperbolic step. Other options are possible, as for example, VOF type methods (Miller and Puckett, 1996). Using a reconstruction algorithm may have nice features when dealing with interfaces only, these interfaces having to be present at the initial time. As we also deal with dynamic appearance of interfaces, a capturing method is preferred.

Regarding the non-conservative energy equations, there is no hope to determine accurate approximation in the presence of shocks (Hou and Le Floch, 1990). Therefore, we use the simplest approximation of the corresponding equations by assuming the product $(\alpha p)_{\mathrm{ki}, \mathrm{j}, 1}^{\mathrm{n}}$ constant during the time step:

$$
\begin{aligned}
& (\alpha \rho \mathrm{e})_{\mathrm{ki}, \mathrm{j}, \mathrm{l}}^{\mathrm{n}+1}=(\alpha \rho \mathrm{e})_{\mathrm{ki}, \mathrm{j}, \mathrm{l}}^{\mathrm{n}} \\
& -\frac{\Delta \mathrm{t}}{\Delta \mathrm{x}}\left(\begin{array}{l}
(\alpha \rho \mathrm{eu})_{\mathrm{ki+1/2,j,1}}^{*}-(\alpha \rho \mathrm{eu})_{\mathrm{ki}-1 / 2, \mathrm{j}, 1}^{*} \\
+(\alpha \mathrm{p})_{\mathrm{ki}, \mathrm{j}, 1}^{\mathrm{n}}\left(\mathrm{u}_{\mathrm{i}+1 / 2, \mathrm{j}, 1}^{*}-\mathrm{u}_{\mathrm{i}-1 / 2, \mathrm{j}, 1}^{*}\right)
\end{array}\right) \\
& -\frac{\Delta \mathrm{t}}{\Delta \mathrm{y}}\left(\begin{array}{c}
(\alpha \rho \mathrm{ev})_{\mathrm{ki}, \mathrm{j}+1 / 2,1}^{*}-(\alpha \rho \mathrm{ev})_{\mathrm{ki}, \mathrm{j}-1 / 2,1}^{*} \\
+(\alpha \mathrm{p})_{\mathrm{ki}, \mathrm{j}, \mathrm{l}}^{\mathrm{n}}\left(\mathrm{v}_{\mathrm{i}, \mathrm{j}+1 / 2,1}^{*}-\mathrm{v}_{\mathrm{i}, \mathrm{j}-1 / 2,1}^{*}\right)
\end{array}\right) \\
& -\frac{\Delta \mathrm{t}}{\Delta \mathrm{z}}\left(\begin{array}{l}
(\alpha \rho \mathrm{ew})_{\mathrm{ki}, \mathrm{j}, \mathrm{l}+1 / 2}^{*}-(\alpha \rho \mathrm{ew})_{\mathrm{ki}, \mathrm{j}, \mathrm{l}-1 / 2}^{*} \\
+(\alpha \mathrm{p})_{\mathrm{ki}, \mathrm{j}, 1}^{\mathrm{n}}\left(\mathrm{w}_{\mathrm{i}, \mathrm{j}, 1+1 / 2}^{*}-\mathrm{w}_{\mathrm{i}, \mathrm{j}, \mathrm{l}-1 / 2}^{*}\right)
\end{array}\right)
\end{aligned}
$$

The lack of accuracy in the internal energy computation resulting from the present scheme is not so crucial. The internal energies will be used only to estimate the phase's pressure at the end of the hyperbolic step, before the relaxation one. The relaxation step will give a first correction to the internal energies, in agreement with the second law of thermodynamics. A second correction will be made with the help of the total mixture energy. The details of these two steps are described in the next subsections.

\section{Relaxation step}

This step is of major importance to fulfill interface conditions in non-uniform velocity and pressure flows. It also 
forces the solution of the pressure non-equilibrium model (3) to converge to that of the equilibrium model (1).

In the relaxation step the system to consider reads,

$$
\begin{aligned}
& \frac{\partial \alpha_{\mathrm{k}}}{\partial \mathrm{t}}=\alpha_{\mathrm{k}} \mu\left(\mathrm{p}_{\mathrm{k}}-\mathrm{p}_{*}\right), \frac{\partial \alpha_{\mathrm{k}} \rho_{\mathrm{k}}}{\partial \mathrm{t}}=0, \\
& \frac{\partial \alpha_{\mathrm{k}} \rho_{\mathrm{k}} \mathrm{e}_{\mathrm{k}}}{\partial \mathrm{t}}=-\alpha_{\mathrm{k}} \mathrm{p}_{\mathrm{I}} \mu\left(\mathrm{p}_{\mathrm{k}}-\mathrm{p}_{*}\right), \\
& \frac{\partial \rho \overrightarrow{\mathrm{u}}}{\partial \mathrm{t}}=\overrightarrow{0}, \frac{\partial \rho \mathrm{E}}{\partial \mathrm{t}}=0
\end{aligned}
$$

in the limit $\mu \rightarrow+\infty$.

After some manipulations the internal energy equations become:

$\frac{\partial \mathrm{e}_{\mathrm{k}}}{\partial \mathrm{t}}+\mathrm{p}_{\mathrm{I}} \frac{\partial \mathrm{v}_{\mathrm{k}}}{\partial \mathrm{t}}=0$

This system can be written in integral formulation as,

$$
\mathrm{e}_{\mathrm{k}}-\mathrm{e}_{\mathrm{k}}^{0}+\hat{\mathrm{p}}_{\mathrm{Ik}}\left(\mathrm{v}_{\mathrm{k}}-\mathrm{v}_{\mathrm{k}}^{0}\right)=0
$$

where $\hat{\mathrm{p}}_{\mathrm{Ik}}=\frac{1}{\mathrm{v}_{\mathrm{k}}-\mathrm{v}_{\mathrm{k}}^{0}} \int_{0}^{\Delta \mathrm{t}} \mathrm{p}_{\mathrm{I}} \frac{\partial \mathrm{v}_{\mathrm{k}}}{\partial \mathrm{t}} \mathrm{dt}$.

Determination of pressure averages $\hat{\mathrm{p}}_{\mathrm{Ik}}$ has to be done in agreement with thermodynamic considerations.

By summing the internal energy equations we have:

$$
\sum_{\mathrm{k}}\left(\mathrm{Y}_{\mathrm{k}} \mathrm{e}_{\mathrm{k}}-\mathrm{Y}_{\mathrm{k}} \mathrm{e}_{\mathrm{k}}^{0}\right)+\sum_{\mathrm{k}} \hat{\mathrm{p}}_{\mathrm{Ik}}\left(\mathrm{Y}_{\mathrm{k}} \mathrm{v}_{\mathrm{k}}-\mathrm{Y}_{\mathrm{k}} \mathrm{v}_{\mathrm{k}}^{0}\right)=0
$$

As the system conserves energy,

$$
\sum_{\mathrm{k}}\left(\mathrm{Y}_{\mathrm{k}} \mathrm{e}_{\mathrm{k}}-\mathrm{Y}_{\mathrm{k}} \mathrm{e}_{\mathrm{k}}^{0}\right)=0
$$

On the other hand, mass conservation implies

$$
\sum_{\mathrm{k}}\left(\mathrm{Y}_{\mathrm{k}} \mathrm{v}_{\mathrm{k}}-\mathrm{Y}_{\mathrm{k}} \mathrm{v}_{\mathrm{k}}^{0}\right)=0
$$

Therefore, the identity,

$$
\sum_{\mathrm{k}}\left(\mathrm{Y}_{\mathrm{k}} \mathrm{e}_{\mathrm{k}}-\mathrm{Y}_{\mathrm{k}} \mathrm{e}_{\mathrm{k}}^{0}\right)+\sum_{\mathrm{k}} \hat{\mathrm{p}}_{\mathrm{Ik}}\left(\mathrm{Y}_{\mathrm{k}} \mathrm{v}_{\mathrm{k}}-\mathrm{Y}_{\mathrm{k}} \mathrm{v}_{\mathrm{k}}^{0}\right)=0
$$

will be fulfilled if the various pressure averages are taken equal, i.e.,

$$
\hat{\mathrm{p}}_{\mathrm{Ik}}=\hat{\mathrm{p}}_{\mathrm{I}}=\mathrm{p}
$$

This pressure average estimate also agrees with the entropy inequality.
The system to solve is thus composed of equations

$\mathrm{e}_{\mathrm{k}}\left(\mathrm{p}, \mathrm{v}_{\mathrm{k}}\right)-\mathrm{e}_{\mathrm{k}}^{0}\left(\mathrm{p}_{\mathrm{k}}^{0}, \mathrm{v}_{\mathrm{k}}^{0}\right)+\hat{\mathrm{p}}_{\mathrm{I}}\left(\mathrm{v}_{\mathrm{k}}-\mathrm{v}_{\mathrm{k}}^{0}\right)=0, \quad \mathrm{k}=1, \mathrm{~N}$

which involves $\mathrm{N}+1$ unknowns, $\mathrm{v}_{\mathrm{k}}(\mathrm{k}=1, \mathrm{~N})$ and $\mathrm{p}$. Its closure is achieved by the saturation constraint,

$\sum_{\mathrm{k}} \alpha_{\mathrm{k}}=1$

That can be rewritten under the form:

$\sum_{\mathrm{k}}(\alpha \rho)_{\mathrm{k}} \mathrm{v}_{\mathrm{k}}=1$

As the $(\alpha \rho)_{\mathrm{k}}$ are constant during the relaxation process, this system can be replaced by a single equation with a single unknown ( $p$ ). With the help of the EOS the energy equations become:

$\mathrm{v}_{\mathrm{k}}(\mathrm{p})=\mathrm{v}_{\mathrm{k}}^{0} \frac{\mathrm{p}_{\mathrm{k}}^{0}+\gamma_{\mathrm{k}} \mathrm{p}_{\infty \mathrm{k}}+\left(\gamma_{\mathrm{k}}-1\right) \hat{\mathrm{p}}_{\mathrm{I}}}{\mathrm{p}+\gamma_{\mathrm{k}} \mathrm{p}_{\infty \mathrm{k}}+\left(\gamma_{\mathrm{k}}-1\right) \hat{\mathrm{p}}_{\mathrm{I}}}$

and thus the only equation to solve (for $\mathrm{p}$ ) is

$\sum_{\mathrm{k}}(\alpha \rho)_{\mathrm{k}} \mathrm{v}_{\mathrm{k}}(\mathrm{p})=1$

Once the relaxed pressure is found, the phase's specific volumes and volume fractions are determined.

However, there is no guarantee that the mixture EOS or the mixture energy be in agreement with this relaxed pressure. In order to respect total energy and correct shock dynamics on both sides of the interface, the following correction is employed.

\section{Reset step}

As the volume fractions have been estimated previously by the relaxation method, the mixture pressure can be determined from the mixture EOS based on the mixture energy which is known from the solution of the total energy equation. As the mixture total energy obeys a conservation law, its evolution is accurate in the entire flow field and in particular at shocks.

Again considering fluids governed by the stiffened gas EOS, the mixture EOS in this context relates mixture energy, density and volume fractions:

$\mathrm{p}\left(\alpha_{\mathrm{k}}, \rho_{\mathrm{k}}, \mathrm{e}\right)=\frac{\rho \mathrm{e}-\sum_{\mathrm{k}}\left(\frac{\alpha_{\mathrm{k}} \gamma_{\mathrm{k}} \mathrm{p}_{\infty \mathrm{k}}}{\gamma_{\mathrm{k}}-1}+\alpha_{\mathrm{k}} \rho_{\mathrm{k}} \mathrm{q}_{\mathrm{k}}\right)}{\sum_{\mathrm{k}}\left(\frac{\alpha_{\mathrm{k}}}{\gamma_{\mathrm{k}}-1}\right)}$ 
This EOS is valid in pure fluids and in the diffuse interface zone. As it is valid in pure fluids and based on the total energy equation, it guarantees correct and conservative wave dynamics on both sides of the interface. Inside the numerical diffusion zone of the interface, numerical experiments show that the method is accurate too, as the volume fractions used in the mixture EOS have a quite accurate prediction from the relaxation method.

Once the mixture pressure is determined the internal energies of the phases are reset with the help of their respective EOS before going to the next time step,

$\mathrm{e}_{\mathrm{k}}=\mathrm{e}_{\mathrm{k}}\left(\mathrm{p}, \alpha_{\mathrm{k}} \rho_{\mathrm{k}}, \alpha_{\mathrm{k}}\right)$.

\section{Summary of the numerical method}

The numerical method can be summarized as follows:

- At each cell boundary solve the Riemann problem of System (4) with the HLLC solver,

- Evolve all flow variables with the Godunov type method,

- Determine the relaxed pressure and especially the volume fraction by solving Equation (5). The Newton method is appropriate for this task.

- Compute the mixture pressure with Equation (6).

- Reset the internal energies with the computed pressure with the help of their respective EOS (7).

- Go to the first item for the next time step.

\section{VALIDATION AGAINST EXPERIMENTS}

The aim of this part is to validate the method regarding its capabilities to compute cavitating flows. Comparisons against experiments done in water tunnel are done. Experiments have been achieved at Chungnam National University (South Korea) on the following geometry:

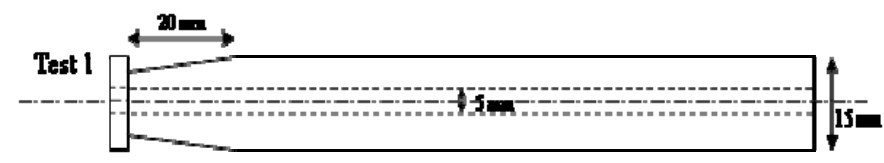

Fig. 2 The solid body is axi-symmetric and possesses a suction hole (delimited by dashed lines).

A water flow is injected from the left boundary condition at the velocity of $25 \mathrm{~m} / \mathrm{s}$. The ambient pressure is taken equal to $2 \mathrm{~atm}$ and is obtained thanks to a right boundary condition with imposed pressure far from the solid body. The other computational domain boundaries correspond to walls. The mesh is presented in the Fig. 3 and computational results are presented at steady state in the Figure 4.

In order to compare with experiments in the same conditions, a cut view is done. Comparisons are presented in the Figure 5.
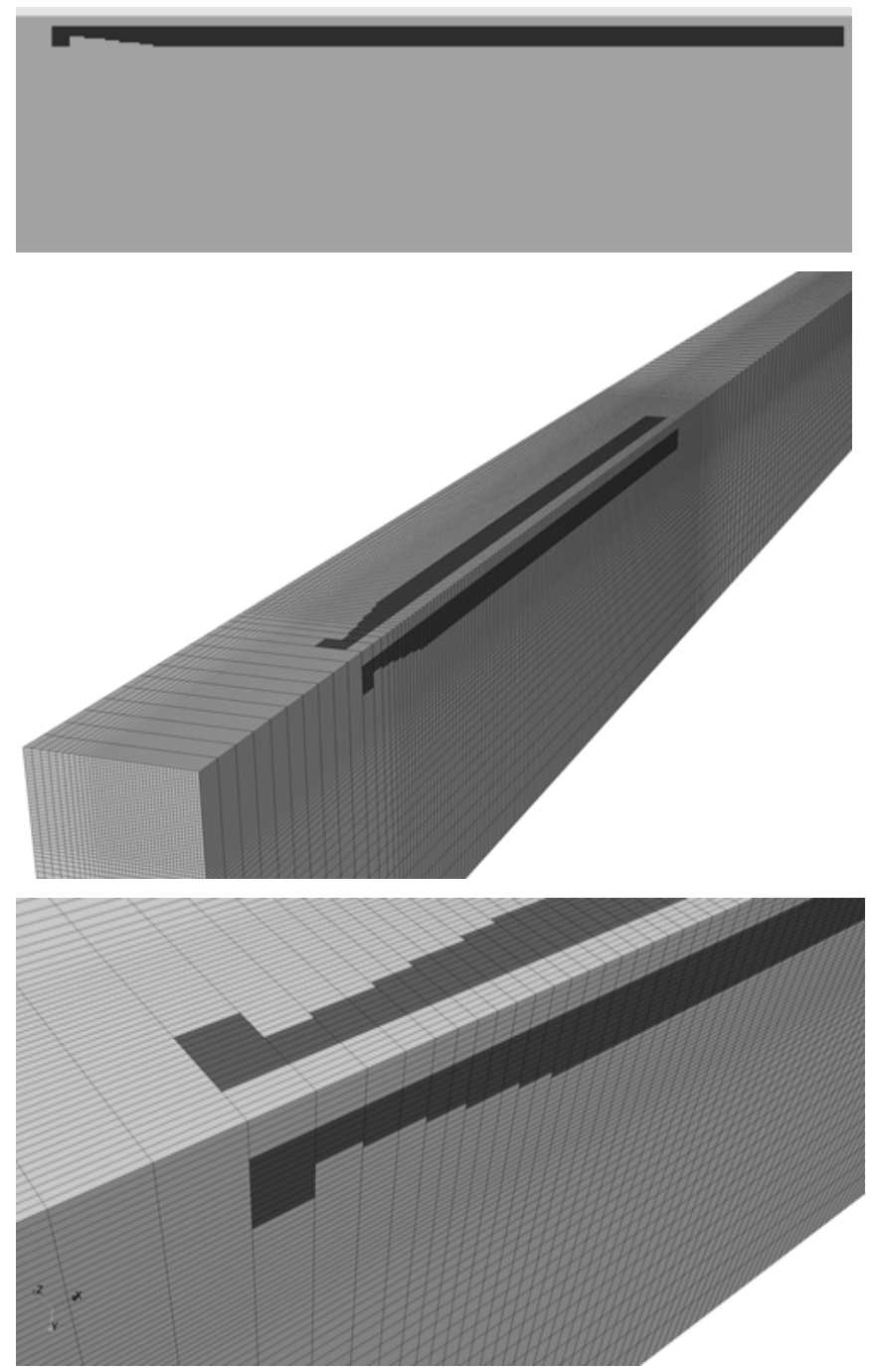

Fig. 3 Mesh used for 3D computations of water tunnel Test case with suction hole. The mesh is composed of 443292 computational cells $(204 \times 53 \times 41)$. The top picture is a general view of the $3 \mathrm{D}$ mesh, the bottom view is magnified around the head of the solid body. Thanks to the symmetry, only a quarter of the physical domain is considered.

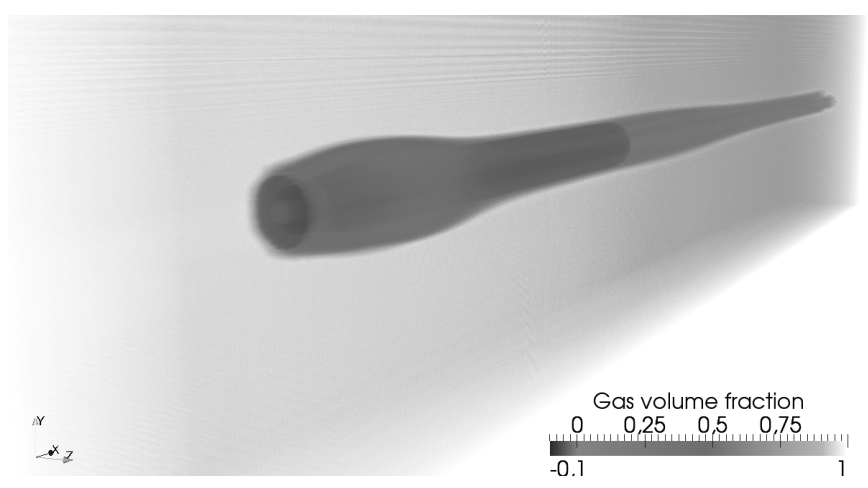

Fig. 4 3D results for solid body with suction hole in water tunnel. Gas volume fraction contours are shown at steady state. The cavitation pocket that develops around the solid body is clearly visible. 


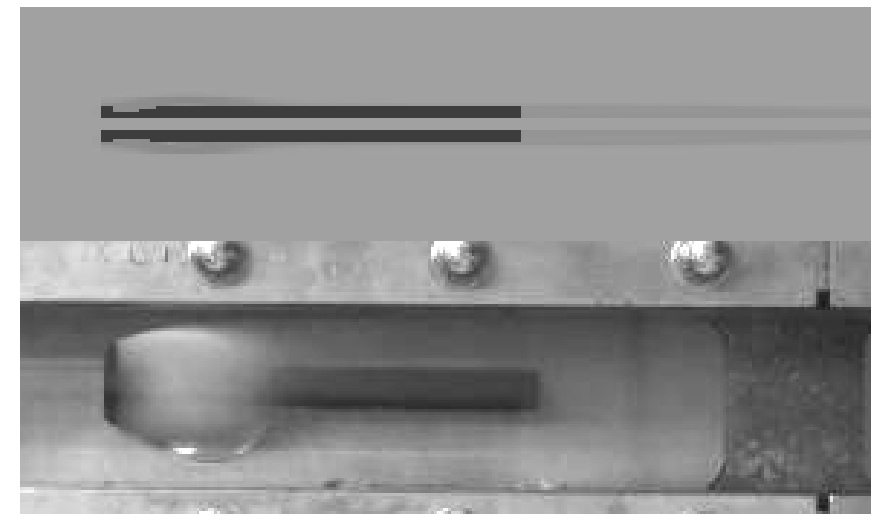

Fig. 5 Validation against experiments at steady state. Results are in perfect agreement.

\section{HIGH SPEED TORPEDO COMPUTATIONS}

The flow model (1) is solved in the multiphase case. The simulation under interest deals with a Shkval like torpedo. The rocket is supposed to travel underwater at the velocity of $50 \mathrm{~m} / \mathrm{s}$ to the left. In the simulations, this motion is modeled by a static rocket (considered as an obstacle for the flow) with a left boundary condition of injection for the computational domain. The rocket is equipped with a nozzle connected to a tank boundary condition. In the tank, a gas at $2500 \mathrm{~K}$ (corresponding to high pressure combustion products) is supposed to be at the constant pressure of $P_{\text {tank }}=25$ bar. The right boundary of the computational domain is an outflow condition and the other boundaries (top, bottom, front and back) are outflow conditions with imposed pressure. The ambient pressure (far from the rocket) depends on the evolution depth of the rocket. In this part, the ambient pressure will be taken equal to 6 bar corresponding to an underwater depth of $50 \mathrm{~m}$. The rocket's head is composed by a solid disk behind which a gas is ejected from an additional tank. In this nose tank, the gas is supposed to be at the temperature of $2500 \mathrm{~K}$ too and at the constant pressure of $P_{\text {nose }}=35 \mathrm{bar}$. The initial configuration is shown in $2 \mathrm{D}$ in the Figure 6:

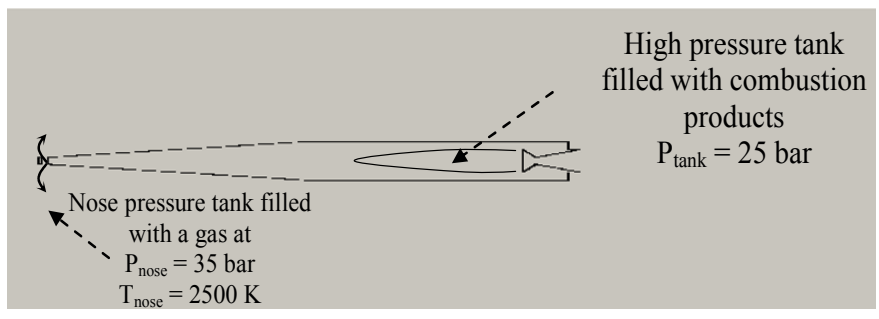

Fig. 6 Initial configuration for the Shkval-like rocket vehicle.

The vehicle length is approximately $8 \mathrm{~m}$ with a maximum radius of $0.25 \mathrm{~m}$. A gas can be injected at the rocket nose just behind the cavitating disc. The total simulated domain size is equal to $20 \mathrm{~m}$ long in the $\mathrm{x}$ direction and $6 \mathrm{~m}$ in $\mathrm{y}$ and $\mathrm{z}$ directions.
The goal is to study the effects of gas injection at the nose as well as the torpedo tilted angle with respect to the flow direction. For that we consider a set of four 3D tests summarized in the following table:

Table 1. Simulated tests summary.

\begin{tabular}{|c|c|c|}
\hline $\begin{array}{c}\text { Gas is injected } \\
\text { at nose }\end{array}$ & $0^{\circ}$ tilted angle & $4^{\circ}$ tilted angle \\
\hline $\begin{array}{c}\text { Without gas injection } \\
\text { at nose }\end{array}$ & Test 2 & Test 3 \\
\hline
\end{tabular}

For each test we determine thrust, lift and drag performances.

\section{Absolute thrust determination}

We consider the rocket engine composed of a tank equipped with a nozzle as schematized in the Figure 7:

We are going to integrate the momentum equation on the system volume composed of both tank and nozzle:

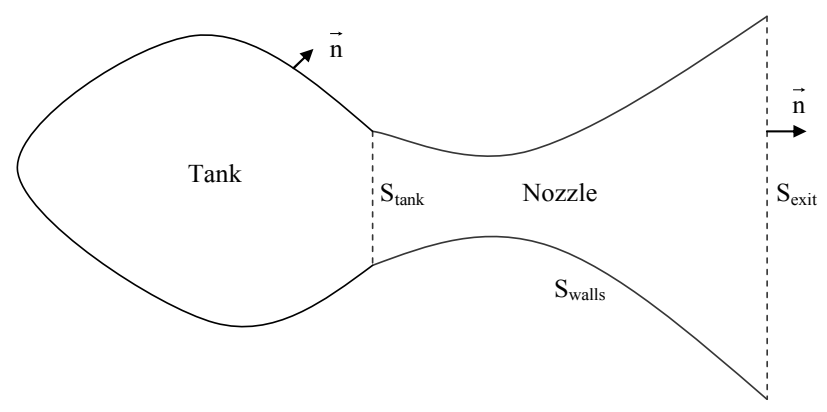

Fig 7. Schematic representation of the rocket engine equipped with a nozzle.

$\int_{\mathrm{V}} \frac{\partial \rho \overrightarrow{\mathrm{u}}}{\partial \mathrm{t}} \mathrm{dV}+\int_{\mathrm{V}} \operatorname{div}(\rho \overrightarrow{\mathrm{u}} \otimes \overrightarrow{\mathrm{u}}+\mathrm{pI}) \mathrm{dV}=\overrightarrow{0}$

Under steady flow assumption, the first integral vanishes and we obtain:

$$
\int_{\mathrm{V}} \operatorname{div}(\rho \overrightarrow{\mathrm{u}} \otimes \overrightarrow{\mathrm{u}}+\mathrm{pI}) \mathrm{dV}=\int_{\mathrm{S}} \rho \overrightarrow{\mathrm{u}}(\overrightarrow{\mathrm{u}} \bullet \overrightarrow{\mathrm{n}}) \mathrm{d} \mathrm{S}+\int_{\mathrm{S}} \mathrm{p} \overrightarrow{\mathrm{n}} \mathrm{dS}=0
$$

Each surface integral can be decomposed in an integral at walls and another one at the nozzle exit. It becomes:

$$
\int_{S_{\text {walls }}} \rho \overrightarrow{\mathrm{u}}(\overrightarrow{\mathrm{u}} \bullet \overrightarrow{\mathrm{n}}) \mathrm{d} S+\int_{S_{\text {exit }}} \rho \overrightarrow{\mathrm{u}}(\overrightarrow{\mathrm{u}} \bullet \overrightarrow{\mathrm{n}}) \mathrm{d} S+\int_{S_{\text {walls }}} \mathrm{p} \overrightarrow{\mathrm{n}} \mathrm{d} S+\int_{S_{\text {exit }}} \mathrm{p} \overrightarrow{\mathrm{n}} \mathrm{d} \mathrm{S}=0
$$

The first integral vanishes due to the velocity slip condition. We thus obtain:

$\int_{S_{\text {exit }}} \rho \overrightarrow{\mathrm{u}}(\overrightarrow{\mathrm{u}} \bullet \overrightarrow{\mathrm{n}}) \mathrm{dS}+\int_{\mathrm{S}_{\text {walls }}} \mathrm{p} \overrightarrow{\mathrm{n}} \mathrm{d} S+\int_{\mathrm{S}_{\text {exit }}} \mathrm{p} \overrightarrow{\mathrm{n}} \mathrm{dS}=0$

We can define the absolute engine thrust by: 
$\overrightarrow{\mathrm{T}}_{\mathrm{abs}}=-\int_{S_{\text {walls }}} \mathrm{pndS}$

Using relation (8), we obtain:

$$
\overrightarrow{\mathrm{T}}_{\mathrm{abs}}=\int_{\mathrm{S}_{\text {exit }}} \rho \overrightarrow{\mathrm{u}}(\overrightarrow{\mathrm{u}} \bullet \overrightarrow{\mathrm{n}}) \mathrm{d} \mathrm{S}+\int_{\mathrm{S}_{\text {exit }}} \mathrm{p} \overrightarrow{\mathrm{n}} \mathrm{d} \mathrm{S}
$$

If we now integrate the momentum equation on the nozzle only, we obtain:

$$
\begin{gathered}
\int_{S_{\text {tank }}} \rho \overrightarrow{\mathrm{u}}(\overrightarrow{\mathrm{u}} \bullet \overrightarrow{\mathrm{n}}) \mathrm{d} \mathrm{S}+\int_{S_{\text {walls }}} \rho \overrightarrow{\mathrm{u}}(\overrightarrow{\mathrm{u}} \bullet \overrightarrow{\mathrm{n}}) \mathrm{d} S+\int_{S_{\text {exit }}} \rho \overrightarrow{\mathrm{u}}(\overrightarrow{\mathrm{u}} \bullet \overrightarrow{\mathrm{n}}) \mathrm{d} S \\
+\int_{S_{\text {tank }}} \overrightarrow{\mathrm{pn}} \mathrm{d} S+\int_{S_{\text {walls }}} \overrightarrow{\mathrm{pn}} \mathrm{d} S+\int_{S_{\text {exit }}} \overrightarrow{\mathrm{n}} \overrightarrow{\mathrm{d}} \mathrm{S}=0
\end{gathered}
$$

Again, the second integral vanishes due to the velocity slip condition. We thus obtain:

$$
\begin{aligned}
\int_{S_{\text {exit }}} \rho \overrightarrow{\mathrm{u}}(\overrightarrow{\mathrm{u}} \bullet \overrightarrow{\mathrm{n}}) \mathrm{d} S & +\int_{S_{\text {exit }}} \overrightarrow{p n} \mathrm{~d} S= \\
& -\int_{\mathrm{S}_{\text {tan k }}} \rho \overrightarrow{\mathrm{u}}(\overrightarrow{\mathrm{u}} \bullet \overrightarrow{\mathrm{n}}) \mathrm{d} S-\int_{S_{\text {tan k }}} \mathrm{p} \vec{n} \mathrm{~d} S-\int_{S_{\text {walls }}} p \vec{n} \mathrm{~d} S
\end{aligned}
$$

Using relation (9), new relation for the absolute thrust is obtained:

$\overrightarrow{\mathrm{T}}_{\mathrm{abs}}=-\int_{\mathrm{S}_{\text {tank }}} \rho \overrightarrow{\mathrm{u}}(\overrightarrow{\mathrm{u}} \bullet \overrightarrow{\mathrm{n}}) \mathrm{d} S-\int_{\mathrm{S}_{\text {tank }}} \mathrm{p} \vec{n} \mathrm{~d} S-\int_{\mathrm{S}_{\text {walls }}} \mathrm{p} \overrightarrow{\mathrm{n}} \mathrm{d} \mathrm{S}$

Relation (10) is preferred for the absolute thrust computation.

\section{Net thrust determination}

The net thrust is determined by a similar reasoning. Considering again the steady momentum equation,

$\int_{V} \operatorname{div}(\rho \vec{u} \otimes \vec{u}+p \overline{\bar{I}}) d V=\int_{S} \rho \vec{u}(\vec{u} \bullet \vec{n}) d S+\int_{S} p \vec{n} d S=0$

integration is done over the entire rocket. As $(\overrightarrow{\mathrm{u}} \bullet \overrightarrow{\mathrm{n}})$ is zero everywhere except in the tank the first surface integral reduces to $-\int_{\mathrm{S}_{\text {tank }}} \rho \overrightarrow{\mathrm{u}}(\overrightarrow{\mathrm{u}} \bullet \overrightarrow{\mathrm{n}}) \mathrm{dS}$. Thus,

In formula (10), the wall surface corresponds to the nozzle one, thus:

$$
\overrightarrow{\mathrm{T}}_{\mathrm{abs}}=-\int_{S_{\text {ank }}} \rho \overrightarrow{\mathrm{u}}(\overrightarrow{\mathrm{u}} \bullet \overrightarrow{\mathrm{n}}) \mathrm{dS}-\int_{S_{\text {annk }}} \mathrm{p} \vec{n} \mathrm{dS}-\int_{S_{\text {walls }} \text {-norzle }} \vec{p} \vec{n} \mathrm{~d} S
$$

The external pressure drag force is defined by:

$$
\overrightarrow{\mathrm{D}}=-\int_{\text {Swalls-body }} \overrightarrow{\mathrm{n}} \mathrm{d} S
$$

Thus, Relation (11) can also be written as:

$\overrightarrow{\mathrm{T}}_{\mathrm{abs}}+\overrightarrow{\mathrm{D}}=0$.

This relation is valid at equilibrium only, when the missile acceleration is zero. Otherwise it reads:

$\overrightarrow{\mathrm{T}}_{\mathrm{abs}}+\overrightarrow{\mathrm{D}}=\mathrm{m} \vec{\gamma}$,

where $\vec{\gamma}$ represents the missile acceleration and $\mathrm{m}$ its mass.

If the sum,

$\overrightarrow{\mathrm{T}}_{\mathrm{abs}}+\overrightarrow{\mathrm{D}}>0$,

is positive, the missile is accelerating. Otherwise it is decelerating.

$$
\begin{aligned}
& \int_{\text {Stan k }} \rho \overrightarrow{\mathrm{u}}(\overrightarrow{\mathrm{u}} \bullet \overrightarrow{\mathrm{n}}) \mathrm{d} S+\int_{\text {Swalls-body }} \overrightarrow{p n d S} \\
& +\int_{\text {Swalls-nozzle }} \overrightarrow{\mathrm{n} d \mathrm{~d} S}+\int_{\text {Stan k }} \overrightarrow{\mathrm{pn}} \mathrm{d} S=0
\end{aligned}
$$

Let us denote by $\vec{T}_{\text {net }}=\vec{T}_{\text {abs }}+\vec{D}$. The net thrust $\vec{T}_{\text {net }}$ is computed numerically from (11) under the form:

$\overrightarrow{\mathrm{T}}_{\text {net }}=-\int_{\mathrm{S}_{\text {tank }}} \rho \overrightarrow{\mathrm{u}}(\overrightarrow{\mathrm{u}} \bullet \overrightarrow{\mathrm{n}}) \mathrm{dS}-\int_{\mathrm{S}_{\text {rocket-toall }}} \overrightarrow{\mathrm{n}} \mathrm{dS}$

\section{Numerical results}

A typical result of simulation at steady state is presented in the Figures 8 and 9. It deals with Test 3 computations. Results obtained for Test 1 to 4 are summarized in the following table:

Table 2. Computed forces for each test case.

\begin{tabular}{|c|c|c|c|c|}
\hline Test $n$ & $T_{\text {net, } x}(k N)$ & $T_{\text {net, } y}(k N)$ & $T_{\text {net, } z}(k N)$ & $T_{\text {abs, } x}(k N)$ \\
\hline 1 & -20 & $\approx 0$ & $\approx 0$ & -73 \\
\hline 2 & 17 & $\approx 0$ & $\approx 0$ & -73 \\
\hline 3 & $\approx 0$ & $\approx 0$ & 200 & -75 \\
\hline 4 & 35 & $\approx 0$ & 300 & -75 \\
\hline
\end{tabular}

Regarding Test 1 and 2, with the $0^{\circ}$ tilted rocket, we recover that the net thrust is nearly equal to 0 in $\mathrm{y}$ and $\mathrm{z}$ directions (in fact not strictly equal to zero due the 3D numerical discrete approximations). In $\mathrm{x}$ direction, absolute thrusts are negative and equal for both Test 1 and 2. This is 
not surprising since the rocket engine is acting for rocket motion in the opposite sense of the $\mathrm{x}$-direction. For the net thrust along $x$-direction, the values are quite different regarding Test 1 and 2. For Test 1, this value is negative, it means that due to the initial conditions (given depth and velocity), the rocket engine is delivering more power than needed. Thus, the rocket is going to accelerate until the net thrust becomes equal to zero. For Test 2, when no gases are injected at the rocket nose, the net thrust becomes positive. This implies that drag forces acting on the rocket become so strong that the rocket is going to decelerate. These results validates that injection gases at nose improve the rocket performance as it reduces drag effects.

Regarding tilted rocket now, corresponding to Test 3 and 4 , the absolute thrust force is nearly the same as for Tests 1 and 2 (here again, some differences can be noticed due to discrete approximations), traducing that inclination of the rocket has no effects on engine performances. For net thrusts in $\mathrm{y}$ direction, we always obtain zero, the flow being symmetric according to plane $\mathrm{xOz}$. We observe that due to inclination, net thrust force in $\mathrm{z}$ direction becomes very strong and positive. This is due to the contact between the rocket body and pure liquid water (as seen in the Figure 8). Here again, gas injection in Test 3 tends to improve rocket performance by decreasing this value as well as the net thrust in the $\mathrm{x}$ - direction.
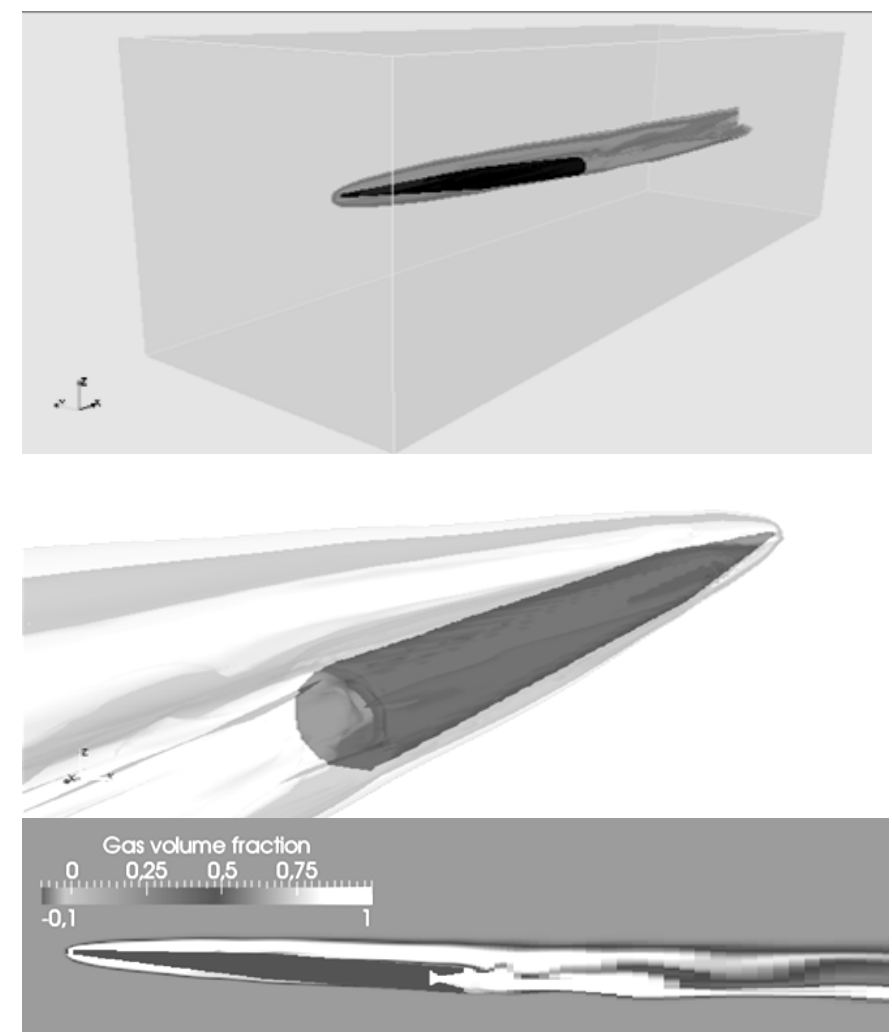

Fig. 8 Results of Test 3: Missile moving at $50 \mathrm{~m} / \mathrm{s}$ under 6 bar of external pressure with a tilted angle of $4^{\circ}$. 3D computational results are shown. In this simulation, a gas is injected at the rocket nose producing a pocket around the missile. Due to the inclination, the pocket is not surrounding the entire missile and liquid water is in contact with the rocket bottom. The two first pictures are front and rear contour views of the gas volume fraction. The last one is a cut view done along the rocket axis showing the gas volume fraction contours.

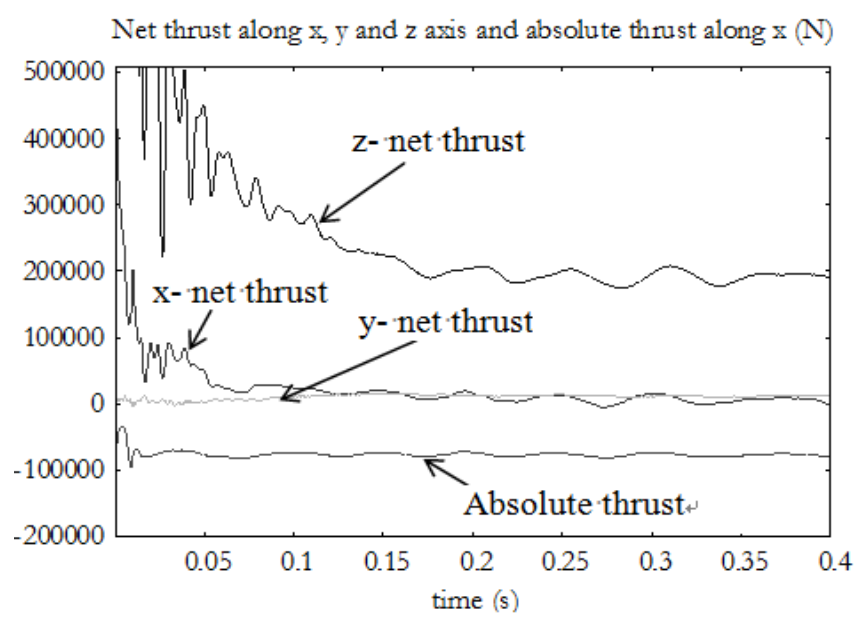

Fig. 9 Performance data for Test 3: Missile moving at $50 \mathrm{~m} / \mathrm{s}$ under 6 bar of external pressure with a tilted angle of $4^{\circ}$. The net thrust acting on the rocket body can be observed (along $\mathrm{x}$ axis in red line, along $\mathrm{y}$ axis in green line and along $\mathrm{z}$ axis in blue line) as well as the absolute thrust delivered by the rear tank of the rocket (purple line). At steady state, the values are:

$T_{\text {net }, x} \approx 0 \mathrm{kN} ; \quad T_{\text {net, } y} \approx 0 \mathrm{kN} ; \quad T_{\text {net }, z} \approx 200 \mathrm{kN} ;$ $T_{a b s, x} \approx-75 \mathrm{kN}$

\section{CONCLUSIONS}

In this paper, a model to treat high speed cavitation has been presented and applied to 3D cavitating flows around realistic torpedoes of Shkval type. Moreover, it has been shown that the formulation allows the determination of performance data regarding rocket motion. In particular, we have shown that gas injection at the nose of such torpedo is of fundamental importance depending on the depth and missile velocity.

\section{REFERENCES}

Davis, S.F., 1988. Simplified second order Godunov type methods. SIAM Journal on Scientific and Statistical Computing, 9, 445-473

Favrie, N. Gavrilyuk, S. and Saurel, R., 2008. Solid-fluid diffuse interface model in cases of extreme deformations. Journal of Computational Physics, 228(16), pp. 60376077. 
Fedkiw, R. Aslam, T. Merriman, B. and Osher, S., 1999. A Non-oscillatory Eulerian Approach to Interfaces in Multimaterial Flows (the Ghost Fluid Method). Journal of Computational Physics, 152(2), pp 457-492.

Glimm, J. Grove, J.W. Li, X.L. Shyue, K.M. Zhang, Q. and Zeng, Y., 1998. Three dimensional front tracking. SIAM Journal on Scientific and Statistical Computing, 19, pp. 703-727.

Hirt, C.W. and Nichols, B.D., 1981. Volume Of Fluid (VOF) method for the dynamics of free boundaries. Journal of Computational Physics, 39, pp. 201-255.

Hou, T.Y. and Le Floch, P., 1994. Why non-conservative schemes converge to the wrong solution: error analysis, Mathematics of Computation, 62, pp. 497-530.

Kapila A.K. Menikoff R. Bdzil J.B. Son S.F. and Stewart D.S., 2001. Two-phase modeling of deflagration-todetonation transition in granular materials : Reduced equations. Physics of Fluids, 13 (10), pp. 3002-3024.

Le Metayer, O. Massoni, J. and Saurel, R., 2004. Elaboration des lois d'état d'un liquide et de sa vapeur pour les modèles d'écoulements diphasiques. Int. J. Thermal Sciences, 43 (3), pp. 265-276.

Le Metayer, O. Massoni, J. and Saurel, R., 2005. Modeling evaporation fronts with reactive Riemann solvers. Journal of Computational Physics, 205, pp 567-610.

Miller, G.H. and Puckett, E.G., 1996. A High-Order Godunov Method for Multiple Condensed Phases. Journal of Computational Physics, 128(1), pp 134-164

Noh, W.F. and Woodward, P., 1976. Simple line interface calculation. Proceedings of the fifth international conference on numerical methods in fluid dynamics, Vol. 59, pp. 330-340.

Perigaud, G. and Saurel, R., 2005. A compressible flow model with capillary effects. Journal of Computational Physics, Vol. 209, pp 139-178.

Petitpas, F. Massoni, J. Saurel, R. Lapebie, E. and Munier, L., 2009a. Diffuse interface model for high speed cavitating underwater systems. International Journal of Multiphase Flow, 35(8), pp. 747-759.
Petitpas, F. Saurel, R. Franquet, E. and Chinnayya, A., 2009b. Modelling detonation waves in condensed materials: Multiphase CJ conditions and multidimensional computations. Shock Waves, 19(5), pp. 377-401.

Saurel, R. Cocchi, J.P. and Butler, P.B., 1999. Numerical study of cavitation in the wake of a hypervelocity underwater projectile. Journal of Propulsion and Power, 15(4), pp. 513 - 522.

Saurel, R. and Abgrall, R., 1999. A multiphase Godunov method for multifluid and multiphase flows. Journal of Computational Physics, 150, pp 425-467

Saurel, R. and Le Metayer, O., 2001. A multiphase model for interfaces, shocks, detonation waves and cavitation. Journal of Fluid Mechanics, Vol. 431, pp 239 - 271

Saurel, R. Le Metayer, O. Massoni, J. and Gavrilyuk, S., 2007. Shock jump relations for multiphase mixtures with stiff mechanical relaxation. Shock Waves, 16(3), pp 209232

Saurel, R. Petitpas, F. and Abgrall, R., 2008. Modeling phase transition in metastable liquids. Application to cavitating and flashing flows. Journal of Fluid Mechanics, 607: 313-350

Saurel, R. Petitpas, F. and Berry, R.A., 2009. Simple and efficient relaxation for interfaces separating compressible fluids, cavitating flows and shocks in multiphase mixtures. Journal of Computational Physics, 228, pp 1678-1712

Saurel, R. Favrie, N. Petitpas, F. Lallemand, M.H. and Gavrilyuk, S., 2010. Modeling dynamic and irreversible powder compaction. Journal of Fluid Mechanics, Vol. 664, pp. 348-396.

Toro, E.F. Spruce, M. and Spears, W., 1994. Restoration of the contact surface in the HLL-Riemann solver. Shock Waves, Vol. 4, pp. 25-34

Von Neuman, J. and Richtmyer, R., 1950. A method for the numerical calculation of hydrodynamic shocks. Journal of Appl. Phys., Vol. 21, pp. 232-237

Wood, A.B. (1930) A textbook of sound. Bell and Sons Ltd, London 